\title{
SMART PARKING ASSISTANCE USING IOT
}

P. Naveen

Assistant Professor, Department of ECE, Kalasalingam Academy of Research and Education Krishnankoil, (India).

E-mail: naveenamp88@gmail.com ORCID: https://orcid.org/0000-0002-5202-2557

Sivakumar Pothiraj Professor, Department of ECE, Kalasalingam Academy of Research and Education Krishnankoil, (India). E-mail: sivapothi@gmail.com ORCID: https://orcid.org/0000-0003-1328-8093

\section{Citación sugerida:}

Naveen, P., y Pothiraj, S. (2021). Smart parking assistance using IoT. 3C Tecnología. Glosas de innovación aplicadas a la pyme, Edición Especial, (noviembre, 2021),355-369. https://doi.org/10.17993/3ctecno.2021. specialissue8.355-369 


\section{ABSTRACT}

There are problems all over the world like the branches of a banyan tree. Population expansion and rapid urbanization in metro cities is also reducing parking space with the increasing ownership rate of vehicles and the amount of traffic congestion. Finding empty parking space in a congested area, especially during peak hours, is an important task for drivers. When people go to business areas, the need for parking is a major issue. This makes it more prone to collisions due to increased fuel consumption, air pollution, stressed motorists and the inability to accurately predict travel time and tightly packed space. The popular principle of "time money" is considered in areas where drivers are forced to waste time circling for the ideal place to park their vehicles. The scheme also mentions the smart parking system of vehicles along with the reservation mode provided to the customers to book the parking slot through IoT (Internet of Things). This saves fuel and time during heavy traffic. It can be used in shopping malls, airports, hospitals and more.

\section{KEYWORDS}

Smart Parking System, IoT, Reservation of free parking space. 


\section{INTRODUCTION}

Altogether, there are 7.6 billion residents in the world, of which about 1.2 billion have their own vehicles parked on the road. As the population grows, so does the demand for vehicles. The need for traffic intensity relates both area and employment to a city and the growing size of the city.

Traffic congestion on the roads causes a lot of accidents. Only a fraction of the total traffic accidents on the roads have occurred primarily for individuals in 15-44 years of life, which is the final creative purchase year for individuals. Most often, poor people with low backgrounds die in road accidents, with nearly one per cent of the 61 people defined as 'take the money to cover the cost of supporting their losses'. According to the World Bank codification, road accidents are estimated to be 1-2 per cent of the GDP of developing countries, or it can be estimated to be more than double the total amount of prosperous aid received by these growing countries worldwide.

Parking is a basic component of a transportation system. Cities and transportation are rich from early human settlements and popular areas have high traffic congestion. This is because travel time is too long and the socio-economic life of the residents is affected by the high loss of fuel consumption, which rapidly increases the amount of carbon in the atmosphere and environmental problems such as pollution. Improper turns are made just as safely as stopping by drivers, not caring about those around the area. Driving too fast in highly congested areas creates conflicts between people. Whether passing another car in a rage or for fun, these road explosions cause many unwanted car accidents every year. These bad attitudes can be avoided if an organization maneuvers to help drivers find an empty parking slot when they need it.

This paper wants to bring out the smart parking system:

1) Aiming to detect and reduce work for drivers looking for empty parking space.

2) Reduce traffic congestion.

3) Must be the best way to find vacant parking space.

4) Avoid accidents caused by traffic. 
The Arduino board is used to identify whether the slot is booked or the car is parked. An online booking application has been developed to pre-book the empty slot in a specific location before they arrive. Once the slot is booked, the slot is registered under the vehicle number. The registered vehicle is only allowed to park in that slot. Unauthorized vehicles are not allowed inside the parking slot without proper permission. This saves time in searching for free parking and avoids rash driving with frustrated drivers who park their vehicle especially on weekends and holidays.

\section{RELATED WORKS}

Currently, many research missions have an excellent parking management in favor of the concept of wireless sensor networks to detect parking information of free spaces.

Tomar, Kaur, and Singh, (2018), explained about the IoT based parking system. An SMS with a personal ID is sent to the customer via the main station, at which time the sensor senses the vehicle entering the reference area. The station will collect information from these centers and display the ID on the display board of the residential area. The path to the free space is appropriately located and will be displayed on the LED screen at the entrance to the available slot road. This system generates an identification number (ID) when the driver approaches the lane to park their vehicle. This ID is a combination of (a) the free parking slot, (b) the last two digits of the vehicle (car) registration number and (c) the last two digits of the occupant's residence number. When a resident sends feet into the area with this unique ID, it mechanically helps the person locate a parking space dedicated to them and helps to park the car. The authority responsible for booking immediately sends an SMS to the user while securing the parking space. The staff in charge of the parking area find the tenant by scanning the unique code in the parking slot through IoT.

Jangid, Verma, and Shankar (2018) discussed the smart private parking solution. The methodology of this study is to (i) detect video on video through the "playback-subtraction method" and (ii) pre-processing methods used to disrupt the noise in the video-image. The moving vehicle is monitored by manipulating the "Gaussian compound model" and a front mask is designed in this process. A snapshot is drawn in order to identify the car's number plate and explored in the number database on the tray to legalize the vehicle for entry into 
the parking slot. To calculate them the vehicle is differentiated into 'cars' and 'bikes' and the driver is taken to the available parking slot.

Stornelli et al. (2018) explains how to locate a vehicle using wireless networks. When the sensor detects the vehicle the output frequency changes according to the deviation. These modifications are cross-view through the digital interface, which includes (a) microcontroller and (b) fast analog-to-digital converter. The all-encompassing role of the system is controlled by the growing energy-saving mechanism; In view of the need to allocate tracking time as well as the function of parked parking time. Data from the sensor is transmitted by a Bluetooth Low Energy (PLE) transmitter to any Bluetooth Low Energy (PLE) device and data server in the nearby atmosphere.

Jyothish et al. (2018) finds Raspberry Pi a system linked to a website that updates the status of parking spaces. Here, the sensors used are ultrasonic sensors. These sensors help to identify the empty slot by calculating the distance by measurement. These predictions of distance predict whether the slot is empty or booked. All of this information has been updated on the website, which was launched using a local-host. Information about the parking space is collected from the database and displayed on the website under the column assigned to the status. The website has been upgraded under the reload task.

In the work of Owayjan et al. (2017), the user manages the parking access system, which he / she will automatically connect to the parking network, establishing the connection between the client mobile and the mall / central network. When the customer enters the parking lot, a map showing the empty and full space on this floor will appear on his / her mobile app so that the customer can choose one of the free places to park his car. The time it takes for the user to park the vehicle is taken into account from the web server so as not to change the time of the user's phone and cause problems with the system. If the customer decides to leave, the navigation begins to show him / her the road to reach his / her car.

Hainalkar and Vanjale (2017) explains the system that uses IR sensors to sense the presence of a car in a car park. The system uses two Android applications for the driver and the traffic police, respectively. When the driver logs into the system, he will receive information about the nearest parking lot, the total number of parking spaces and the number of vacant parking spaces. When the user reaches the parking space, it will be authenticated using an 
RFID tag and then the gate will open. When the user enters the parking lot before parking at the booked location, he or she must change the RFID tag, which will then only open at the gate of the respective parking lot. The location of the car park will be detected by the IR sensor and delivered in real time to the local unit. Once the car enters the parking lot, billing will begin based on the time the car was parked.

In the work of Wang and He (2011) it is often suggested that ZigBee sensors are widely used to constantly measure parking status for every available parking lot. Each sensor is specifically mixed with (a) $8 \mathrm{MHz}$ microcontroller, (b) 8 channels A / D and (c) 250kbps [802.15.4 wireless radio] with 2 wireless modes. This mode is connected to the contact module via Bluetooth. Communication is connected via a sensor between the Bluetooth module in ZigBee mode and smartphones. If the vehicle is detected in a booked parking lot, the sensor confirms the user's identity. With smartphones, information on parking spaces is available and the specific parking slot can be booked through the web server throughout the area. The Bluetooth module is connected by receiving mobile phones, with the benefit of interacting with sensors when the driver is identified for verification.

In the paper of Nandyal, Sultana, \& Anjum (2017), control the parking space using the Arduino UNO. The following tasks will be performed regarding the arrival of the vehicle in the parking area: (1) the driver stops the vehicle in the detected blank slot, (2) when the vehicle occupies the slot, the LED is determined to flash with a certain color, and, (3) when the slot is empty again, this LED The ED lights will turn off automatically, indicating that the parking lot is empty and not yet occupied by another vehicle. These processes are carried out whenever necessary.

Ling et al. (2017), in his work, have an effective parking order. The recommended configuration uses a single camera attached to an IoT rim device to monitor the condition of street parking spaces within its view. This system will identify the free slot with camerabased view and this data will be stored in the AWS database.

The work by Nimble et al. (2016), proposes a smart parking system powered by number plate authentication technology to improve a sovereign car parking system that uses a number of vehicles to enable image processing concepts. The image of the vehicle license plate is obtained by process and preserved in the database. It is further fragmented to 
have each and always y character on the number plate for the purpose of authentication. The ultrasonic sensor helps detect empty parking spaces in the surrounding area. These images of the number plate are taken into account, analyzed and considered for future use. Correspondingly, the current parking time of the car is also recorded to calculate the parking fee. The LCD screen displays the status as "Complete", indicating that 'there is currently no free parking slot in this area'.

\section{PROPOSED SMART PARKING SYSTEM}

\subsection{MOTOR}

A direct current (DC) motor has been developed to convert electrical energy into mechanical energy. Motor shield 4 or 6 DC motors can run in both forward and reverse directions.

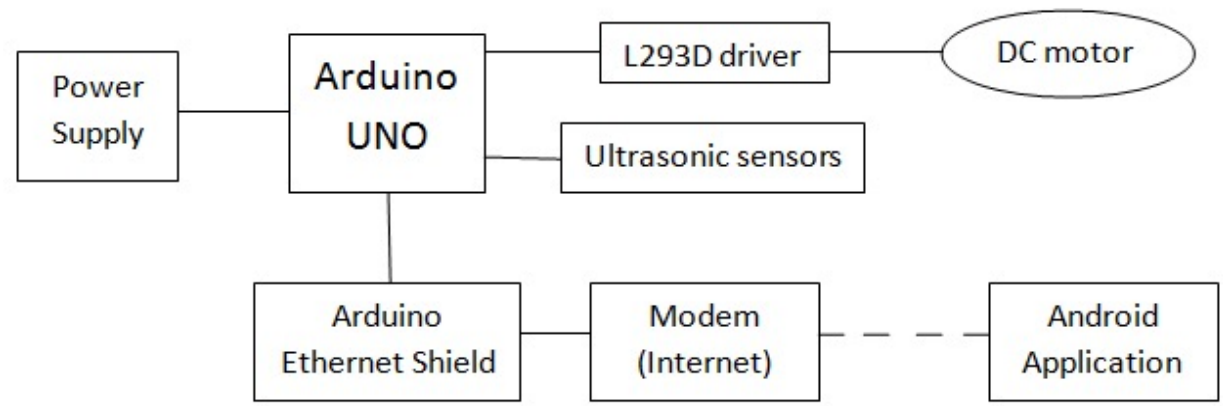

Figure 1. Block diagram of IPA.

Source: own elaboration.

\subsection{L293D DRIVER}

The L293D is a specific type of motor that is used to drive a motor in one direction. It controls a pair of DC motors simultaneously in any other direction. The single L293D drive can be used to control two DC motors without any problems.

\subsection{ARDUINO UNO}

The Arduino UNO R3 is a control board that is completely dependent on the ATmega328. It mainly consists of: (a) 14 digital input / output pins, (b) 6 analog inputs, (c) $16 \mathrm{MHz}$ quartz crystal, (d) USB connector. The operating voltage is $5 \mathrm{~V}$. Flash memory is $32 \mathrm{~KB}$, 
2KB of SRAM and $1 \mathrm{~KB}$ of EEPROM. Power is provided via USB connection or external power supply.

\subsection{ULTRASONIC SENSORS}

Ultrasonic sensors are used to give the distance of any object with the help of sound waves. You can add the remote range of the device. It measures sound waves at a certain frequency and measures the distance by listening to the sound waves returning to its wavelength. Formula for calculating distance:

Distance $=($ Speed of Sound X Time taken $) / 2$.

\subsection{ARDUINO ETHERNET SHIELD}

The Arduino Ethernet shield makes it easy to connect the Arduino to the Internet. It enables sending and receiving data from around the world through an internet connection. It has an on-board microSD slot that allows you to store data and service the website using the Arduino board. An external SD card can be used to store a lot of information as a database. This shield must be connected to a standard Ethernet cable (eg: CAT6 with CAT5 or RJ45 connection).

\subsection{ANDROID APPLICATION}

An Android app called "iBarker" is used to book empty parking spaces in commercial areas such as shopping malls and theaters. This application has been developed in Android Studio for use in public places. This application creates an account and saves, reserves a blank slot and has a timer that runs when the car is parked in the slot.

Steps of application:

(i) The user creates an account or logs in directly to the account if required.

(ii) The user must select a specific interest.

(iii) If seats are vacant, it can be booked. Otherwise, the application will be updated simultaneously each time.

(iv) Once the slot is booked, the timer level is set to zero. When the car is parked in the slot, the timer level is activated and the rate is calculated according to the time. 


\section{METHODOLOGY}

The Arduino UNO board is used to control the operation and motor control of the sensors. Motor control is used to indicate the status of the two ultrasonic sensors used.

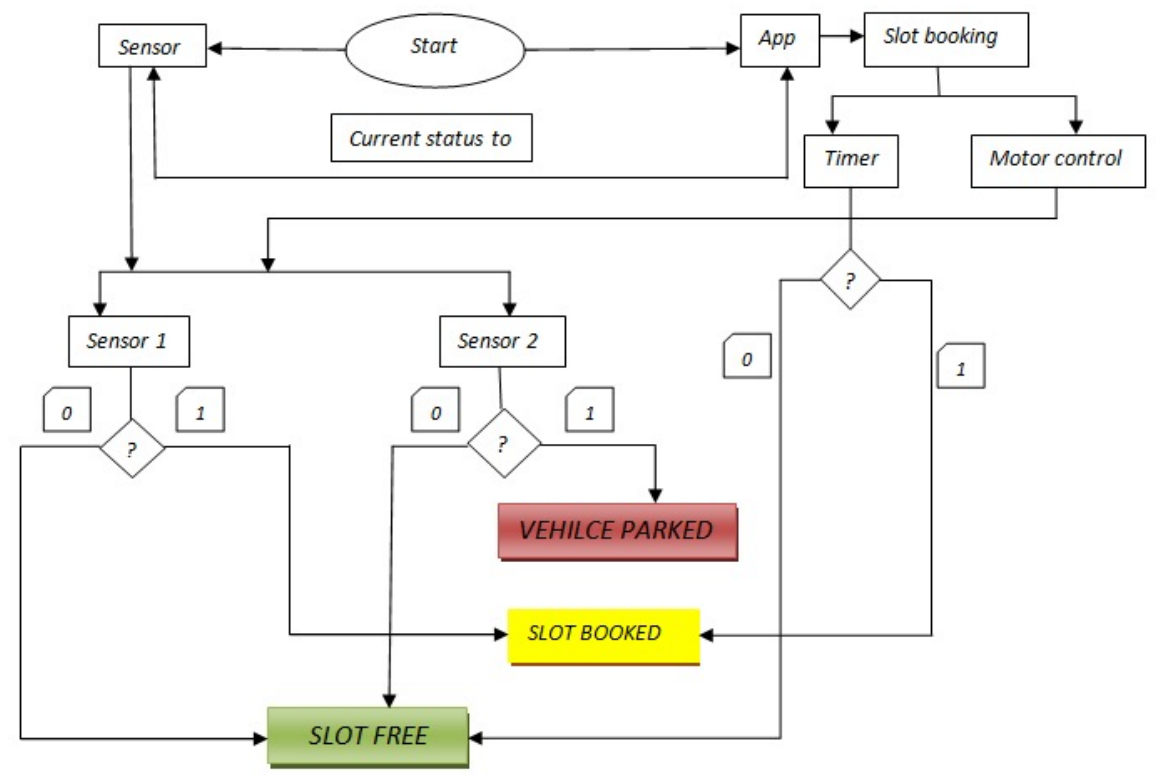

Figure 2. Working of the smart parking system.

Source: own elaboration.

Two sensors are motor-controlled, which are used to indicate the following:

- Sl slot booked or not.

- Car Whether the car is parked or not.

Once the user logs in through the app, the user can book a free slot available wherever they want. This is a place where you can drive without tension towards that area and have safe and sound parking. When the slot is free, it is marked "green". When a free slot is booked by a user, it is marked with a "yellow" color.

When the car is parked in a particular slot, it is marked as "red".

The Android application algorithm works in the following way: 
Initialize

If $(\operatorname{login}==1)$

Get user $x$ and y;

Read selection of $\mathrm{RS}=($ City $)$ If $($ City $==x)$

Read of Area $=($ Area $)$

If $($ Area $==y)$

Read of Area $=($ Area $)$

Write the slots current status $=($ Current status $)$ Sample booking $(1)$ :

If (booking $==$ slot number)

Write booked (slot number) \&\& (motor control) Else

Write (slot free)

If $($ Vehicle $==$ Set $)$

Write booked (Slot number) \&\& (Vehicle

Parked) Else

Write (Slot free)

Write (Current status to login page)

End 


\section{RESULT}

Table 1. Overall hardware output.

\begin{tabular}{|c|c|c|}
\hline Status of the slot & Color allotted & Working of motor \\
\hline Slot free & Green & Not running \\
\hline Slot booked & Yellow & Running in forward direction \\
Vehicle parked & Red & Running in forward and reverse direction \\
\hline
\end{tabular}

Source: own elaboration.

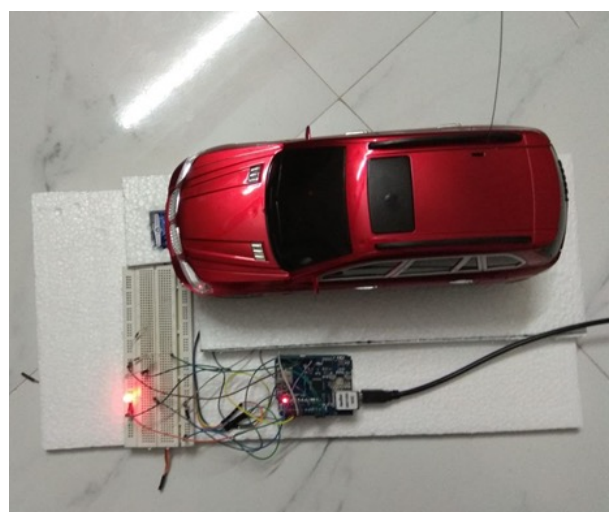

Figure 3. Vehicle is parked indicated through Red LED.

Source: own elaboration.

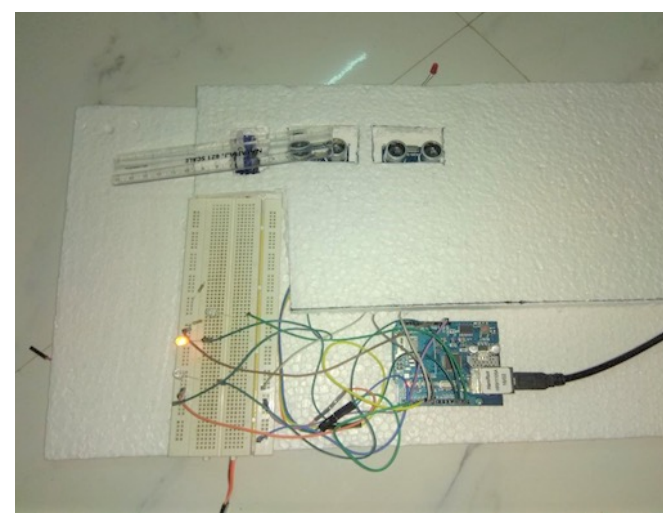

Figure 4. Slot booked indication through Yellow LED.

Source: own elaboration. 


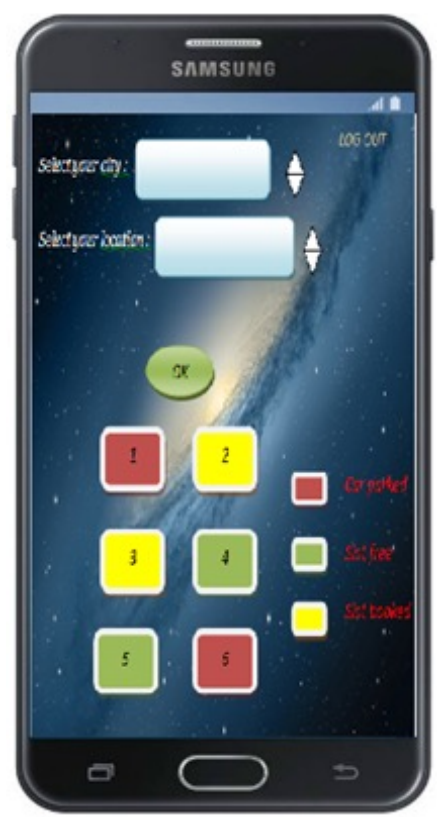

Figure 5. Screenshot of "iParker" Android Application images.

Source: own elaboration.

\section{CONCLUSIONS}

In our paper there is a developed version of the smart parking system. The system has implemented a smart parking system with online booking through an Android application. This system helps to save our time in this busy world. This optimal parking system has a computerized approach to parking issues, which effectively controls traffic congestion during peak hours during business hours. This system helps to avoid excessive traffic, which leads to lower fuel consumption and the content of $\mathrm{CO} 2$ in the atmosphere. Our parking system allows us to book empty parking spaces for easy parking without creating traffic. This system reduces the rate of accidents per year due to traffic.

\subsection{FUTURE ENHANCEMENT}

For future works, we can upgrade our project through online payment. This method of net payment is enough to rent the parking space for the time they need and use it properly. 


\section{REFERENCES}

Al-Absi, H. R. H., Devaraj, J. D. D., Sebastian, P., \& Voon, Y. V. (2010). VisionBased Automated Parking System. In 10th International Conference on Information Science, Signal Processing and their Applications (ISSPA 2010). https://ieeexplore.ieee.org/ document/5605408

Ashokkumar, K., Sam, B., Arshadprabhu, R., \& Britto. (2015). Cloud Based Intelligent Transport System. Procedia Computer Science, 50, 58-63. https://doi. org/10.1016/j.procs.2015.04.061

Geng, Y., \& Cassandras, G. G. (2013). A New Smart Parking System Based on Optimal Resource Allocation and Reservations. In 2011 14th International IEEE Conference on Intelligent Transportation Systems (ITSC). https://ieeexplore.ieee.org/ document/6082832

Hainalkar, G. N., \& Vanjale, M. S. (2017). Smart parking system with pre \& post reservation, billing and traffic app. In 2017 International Conference on Intelligent Computing and Control Systems (ICICCS). https: / / ieeexplore.ieee.org/document/8250772

Jangid, M., Verma, V. K., \& Shankar, V. G. (2018). Counting and Classification of Vehicle Through Virtual Region for Private Parking Solution. In Somani, A., Srivastava, S., Mundra, A., Rawat, S. (eds.) Proceedings of First International Conference on Smart System, Innovations and Computing. Smart Innovation, Systems and Technologies, vol 79. Springer, Singapore. https://doi.org/10.1007/978-981-10-5828-8_72

Ji, Z., Ganchev, I., O’Droma, M., \& Zhang, X. (2014). A cloud-based intelligent car parking services for smart cities. In 2014 XXXIth URSI General Assembly and Scientific Symposium (URSI GASS). https://www.ursi.org/proceedings/procGA14/papers/ ursi_paper2465.pdf

Jyothish, J., Mamatha, Gorur, S., \& Dakshayini, M. (2018). Booking Based Smart Parking Management System. Springer Nature. https://www.springerprofessional.de/en/ booking-based-smart-parking-management-system/15312178 
Ling, X., Sheng,J., Baiocchi, O., Liu, X., \& Tolentino, M. E. (2017). Identifying Parking Spaces \& Detecting Occupancy Using Vision-based IoT Devices. In 2017 Global Internet of Things Summit (GIo TS). https://ieeexplore.ieee.org/document/8016227

Nandyal, S., Sultana, S., \& Anjum, S. (2017). Smart Car Parking System using Arduino UNO. International Fournal of Computer Applications, 169(1). https://www.ijcaonline. org/archives/volume169/number1/nandyal-2017-ijca-914425.pdf

Nawaz, S., Efstratiou, G., \& Mascolo, G. (2017). Parksense: A smartphone based sensing system for on street parking. In MobiCom '13: Proceedings of the 19th annual international conference on Mobile computing $\mathcal{E}^{2}$ networking. https://dl.acm.org/ doi/10.1145/2500423.2500438

Nimble,J., Bhegade, P., Surve, S., \& Chaugule, P. (2016). Automatic Smart Car Parking System. International Fournal of Advances in Electronics and Computer Science, 3(3). http:// www.iraj.in/journal/journal_file/journal_pdf/12-237-145898585349-51.pdf

Owayjan, M., Sleem, B., Saad, E., \& Maroun, A. (2017). Parking Management System Using Mobile Application. In 2017 Sensors Networks Smart and Emerging Technologies (SENSET). https://ieeexplore.ieee.org/document/8125048

Pham, T. N., Tsai, M.-F., Nguyen, D. B., Dow, G.-R., \& Deng, D.-J. (2017). A CloudBased Smart-Parking System Based on Internet-of-Things Technologies. IEEE Access, 3, 1581-1591. https://ieeexplore.ieee.org/document/7247632

Shiyao, G., Ming, W., Chen, L., \& Na, R. (2014). The Research and Implement of the Intelligent Parking Reservation Management System Based on ZigBee Technology. In ICMTMA '14: Proceedings of the 2014 Sixth International Conference on Measuring Technology and Mechatronics Automation, pp. 741-744. https://dl.acm.org/doi/10.1109/ ICMTMA.2014.182

Stornelli, V., Ferri, G., Muttillo, M., Pantoli, L., Leoni, A., Barile, G., D’Onofrio, D., Parente, F. R., \& Gabriele, T. (2018). Wireless Smart Parking Sensor System for Vehicles Detection. In Leone, A., Forleo, A., Francioso, L., Capone, S., Siciliano, P., Di Natale, C. (eds.) Sensors and Microsystems. AISEM 2017. Lecture Notes in Electrical 
Engineering, vol 457. Springer, Cham. https://doi.org/10.1007/978-3-319-668024_25

Tomar, P., Kaur, G., \& Singh, P. (2018). A Prototype of Io T-Based Real Time Smart Street Parking System for Smart Cities. Springer International Publishing AG.

Vishwanath, Y., Kuchalli, A. D., \& Rakshit, D. (2016). Survey paper on Smart Parking System based on Internet of Things. Corpus ID: 40052314. https://www. semanticscholar.org/paper/Survey-paper-on-Smart-Parking-System-based-on-ofVishwanath-Kuchalli/cc5e790e49fe1f00cbd8a6b43527682b87b3d798

Wang, H., \& He, W. (2011). A Reservation-based Smart Parking System. In 2011 IEEE Conference on Computer Communications Workshops (INFOCOM WKSHPS). https:// ieeexplore.ieee.org/document/5928901

Yang, F. M. (2010). Android Application Development Revelation. China Machine Press.

Zanella, A., Bui, N., Castellani, A., Vangelista, L., \& Zorzi, M. (2014). Internet of things for smart cities. IEEE Internet Of Things fournal, 1(1), 22-32. https:/ / ieeexplore. ieee.org/document/6740844 